\title{
Postharvest Control of Botrytis cinerea Infections on Cut Roses Using Fungistatic Storage Atmospheres
}

\author{
Philip E. Hammer ${ }^{1}$, S.F. Yang ${ }^{2}$, M.S. Reid ${ }^{3}$, and J.J. Marois ${ }^{4}$ \\ University of California, Davis, CA 95616 \\ Additional index words. Rosa hybrids, controlled atmosphere storage, carbon dioxide, sulfur dioxide
}

\begin{abstract}
The effectiveness of fungistatic atmospheres for postharvest control of Botrytis cinerea Pers. infections on cut rose flowers (Rosa hybrids L.) was investigated. Storing cut 'Sonia', 'Royalty', and 'Gold Rush' roses at 2.5C with $10 \% \mathrm{CO}_{2}$ for 5 days, followed by 2 days of cold storage in air, reduced the number of $B$. cinerea lesions that developed on inoculated and noninoculated flower petals by $77 \%$ and $82 \%$, respectively, compared to cold storage for 7 days in air. Higher $\mathrm{CO}_{2}$ concentrations and longer $\mathrm{CO}_{2}$ treatment times reduced disease severity further, but resulted in unacceptable leaf discoloration on some cultivars. No deleterious effects of $\mathrm{CO}_{2}$-enriched storage atmospheres on flower quality, weight gain, or vase life were observed. Storage at $2.5 \mathrm{C}$ for 7 days in $2 \mu \mathrm{SO} \mathrm{SO}_{2} /$ liter reduced $B$. cinerea infections on inoculated and noninoculated flowers by $53 \%$ and $43 \%$, respectively. No deleterious effects on flower quality, weight gain, or vase life were observed. Higher $\mathrm{SO}_{2}$ levels reduced disease severity further, but caused bleaching of the petal margins and necrosis around leaf wounds.
\end{abstract}

Botrytis cinerea is a serious pathogen of rose flowers and other cut flower crops. Infections first appear as water-soaked spots or flecks on the flower petals. As the lesions coalesce, the infected petals turn brown and wither. Eventually, the entire flower may rot off at the receptacle. B. cinerea infections often cannot be detected at harvest, but develop rapidly under the moist conditions encountered during storage and transit. Such infections cause major postharvest losses and are considered a limiting factor in the storage and shipment of cut flowers (Carre, 1984; Cline and Bardsley, 1984; McCain and Welch, 1982).

Low storage temperatures slow the development of $B$. cinerea infections (Maude, 1980), but do not always provide adequate control for long-term storage or when inoculum loads are high. At present, many rose growers dip cut flowers in fungicides to prevent postharvest development of $B$. cinerea infections, but this practice leaves unsightly residues on the flowers and foliage (McCain and Welch, 1982).

Fungistatic atmospheres are used to control B. cinerea infections on certain commodities during storage and shipment (Maude, 1980). The atmospheres can be applied in storage rooms or shipping containers and do not leave the unsightly residues associated with most fungicide dip treatments. Carbon dioxideenriched atmospheres are used to minimize Botrytis rot of strawberry fruit during truck shipment (Harvey, 1982). Phillips et al. (1985) found that atmospheres containing $10 \%$ to $30 \% \mathrm{CO}_{2}$ significantly reduced Botrytis flower rot of roses stored at 10 to 12C for 6 days, but Joyce and Reid (1986) reported foliar damage to 'Sonia' roses after storage for 7 days at $1 \mathrm{C}$ in $\mathrm{CO}_{2}$ concentrations as low as $7 \%$.

Sulfur dioxide-enriched atmospheres are used to control de-

Received for publication 5 July 1988. This research was supported, in part, by a National Science Foundation Graduate Fellowship (P.E.H.), by a grant from the Joseph H. Hill Memorial Rose Foundation (J.J.M.), and by the generous donation of roses by the Ninomiya Nursery Co., Richmond, Calif. The cost of publishing this paper was defrayed in part by the payment of page charges. Under postal regulations, this paper therefore must be hereby marked advertisement solely to indicate this fact.

'Graduate student, Dept. of Vegetable Crops. Present address: Dept. of Horticulture, The Pennsylvania State Univ., University Park, PA 16802.

${ }^{2}$ Professor, Dept. of Vegetable Crops.

${ }^{3}$ Professor, Dept. of Environmental Horticulture.

${ }^{4}$ Associate Professor, Dept. of Plant Pathology. cay of table grapes caused mainly by $B$. cinerea during storage and transoceanic shipment (Nelson, 1985). Longley (1933) reported damage to roses stored in $\mathrm{SO}_{2}$ concentrations of $5 \mu \mathrm{l} \cdot$ liter $^{-1}$ or higher. Concentrations of 200 to $5000 \mu \mathrm{l} \cdot$ liter $^{-1}$ typically are used for weekly fumigation of grapes, but continuous exposure to low levels $\left(<10 \mu \mathrm{l} \cdot\right.$ liter $\left.^{-1}\right)$ is also effective for controlling decay (Dahlenburg et al., 1979). The objectives of the present study were to determine the feasibility of using $\mathrm{SO}_{2}-$ or $\mathrm{CO}_{2}-$ enriched storage atmospheres for postharvest control of $\mathrm{B}$. $\mathrm{Ci}$ nerea infections on cut rose flowers.

\section{Materials and Methods}

Botrytis cinerea conidia were washed from 9- to 12-day-old cultures of three separate isolates that were grown as described by Hammer and Marois (1988). The conidia were combined, diluted to $\approx 1000 / \mathrm{ml}$ in deionized water, and sprayed onto the flower petals using a Chromist spray unit (Gelman Sciences, Ann Arbor, Mich.). Noninoculated controls, sprayed with deionized water, were included to monitor background disease levels (those infections not resulting from laboratory inoculation).

Three cultivars of cut roses-'Royalty', 'Sonia', and 'Gold Rush' —were obtained from a commercial grower. The stems were recut $30 \mathrm{~cm}$ below the receptacles and all leaves, except the top two or three, were removed. An experimental unit consisted of three flowers in a 0.5 -liter bottle containing $200 \mathrm{ml}$ of preservative solution (Hammer and Marois, 1988). After inoculation, the roses were stored in 16-liter glass chambers at 2.5 $\pm 1 \mathrm{C}$. Test atmospheres were introduced at the top of each chamber above the flowers and exhausted from the bottom. The atmospheres were humidified and condensation was present on the petals throughout storage. The roses were removed from cold storage 7 days after inoculation and disease severity was quantified as the number of lesions on each flower. Subsequently, opening and vase life were evaluated for 7 days at 21 $\pm 1 \mathrm{C}$, as described by Hammer and Marois $(1988,1989)$. Fresh weight was recorded daily.

Experiment I. 'Royalty' and 'Sonia' roses were inoculated and stored at $2.5 \mathrm{C}$ in air mixed with $0 \%, 5 \%, 10 \%$, or $20 \%(\mathrm{v} /$ v) $\mathrm{CO}_{2}$. The flow rate was $10 \mathrm{Iiter} \cdot \mathrm{hr}^{-1}$ through each chamber. Carbon dioxide treatments were applied for 3, 5, or 7 days, and 
then the roses were stored in air for 4,2, or 0 days, respectively, for a total cold storage period of 7 days. Inoculated control roses were stored in air for the entire 7 days. Seven days after removal from storage, the treatments were ranked subjectively for $\mathrm{CO}_{2}$ induced leaf damage.

This experiment was a complete factorial with four $\mathrm{CO}_{2}$ concentrations and three treatment times. There were three flowers of each cultivar for each factor-level combination. A regression model was fit using reciprocal transformation of $\mathrm{CO}_{2}$ concentration to linearize the function. Carbon dioxide treatment durations were included in the model using indicator variables, and partial $\mathrm{F}$ tests were used to compare the estimated regression functions for 3- and 5-day treatment with that for 7-day treatment.

Experiment II. Roses were stored in air mixed with $0 \%, 5 \%$, $10 \%$, or $15 \% \mathrm{CO}_{2}$ for the first 5 days of storage at $2.5 \mathrm{C}$, then in air for the final 2 days of cold storage. The flow rate was 10 liter $\cdot \mathrm{hr}^{-1}$ through each chamber and $\mathrm{CO}_{2}$ concentrations were confirmed by gas chromatography. Carbon dioxide-induced leaf damage was scored 7 days after removal from storage using the following hedonic scale: $0=$ no visible damage; $1=$ leaves darker green than controls, no more than five small flecks of brown discoloration; 2 = brown discoloration in a mosaic pattern, $<30 \%$ of the leaf area involved; $3=$ obvious brown discoloration, $30 \%$ to $60 \%$ of the leaf area discolored; and $4=$ severe dark brown discoloration, $>60 \%$ of the leaf area discolored. The rating for each rose was based on the most severely discolored leaf. A rating of 3 or greater was considered commercially unacceptable.

This experiment was a complete factorial with four $\mathrm{CO}_{2}$ concentrations, two inoculation levels (inoculated and noninoculated), and three cultivars in a split-plot design. Carbon dioxide concentration and inoculation were the main-plot factors and cultivar was the subplot factor. A main plot consisted of a 15liter storage chamber and contained three subplots $(0.5$-liter bottles). There were two replicates (bottles) of each factor-level combination, with three observations (roses) per replicate. The experiment was repeated and the data were pooled for analysis.

Analysis of variance and $F$ tests $(\alpha=0.05)$ were used for

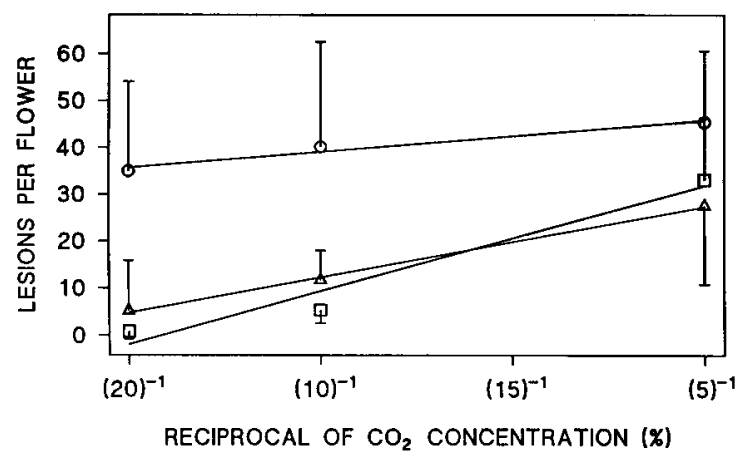

Fig. 1. Effects of $\mathrm{CO}_{2}$ concentration and treatment duration on development of $B$. cinerea lesions on rose flowers during storage at 2.5C (Expt. I). All flowers were inoculated. Mean disease severity on inoculated control flowers (stored in air for 7 days) was 51 lesions per flower. Points are the means of six flowers \pm SD. Reciprocal transformation of $\mathrm{CO}_{2}$ concentration was used to linearize the regression function, and treatment durations were included in the model using indicator variables. Equations are: 3-day $\mathrm{CO}_{2}$ treatment $(\mathrm{O}) \mathrm{Y}$ $=32.3+67.6(\mathrm{X}) ; 5$-day $\mathrm{CO}_{2}$ treatments $(\triangle) \mathrm{Y}=-2.8+$ 150.2(X); 7-day $\mathrm{CO}_{2}$ treatment (ם) $\mathrm{Y}=-13.1+224.5(\mathrm{X})$. For the model as a whole, $R^{2}=0.61$ and $P<0.001$. all data to identify significant main effects and interactions. In all cases, the three-way interactions were found to be nonsignificant and were dropped from the models. Where significant two-way interactions were found, the data were grouped by cultivar and/or by inoculation for further analysis. Quadratic regression models were fit to the disease severity data. For the fresh weight, leaf damage, and vase life data, no meaningful regression models were found. Thus, pairwise and multiple comparison procedures were used to separate means.

Experiment III. Sulfur dioxide treatments were applied for the full 7 days of storage at $2.5 \mathrm{C}$. The flow rate was $15 \mathrm{li}$ ters $\cdot \mathrm{hr}^{-1}$ through each chamber and $\mathrm{SO}_{2}$ concentrations were monitored using a fluorescence detector (Model 8850, Monitor Laboratories, San Diego, Calif.). The inlet $\mathrm{SO}_{2}$ concentrations were $0,0.5,1.0,2.0$, and $4.0 \mu \mathrm{l} \cdot$ liter $^{-1}$, and the steady-state $\mathrm{SO}_{2}$ concentrations at the exhausts were $\approx 0,0.03,0.10,0.25$ and $0.75 \mu \mathrm{l} \cdot$ liter $^{-1}$, respectively. Vase solutions were replaced after storage to minimize possible poststorage effects of bisulfite

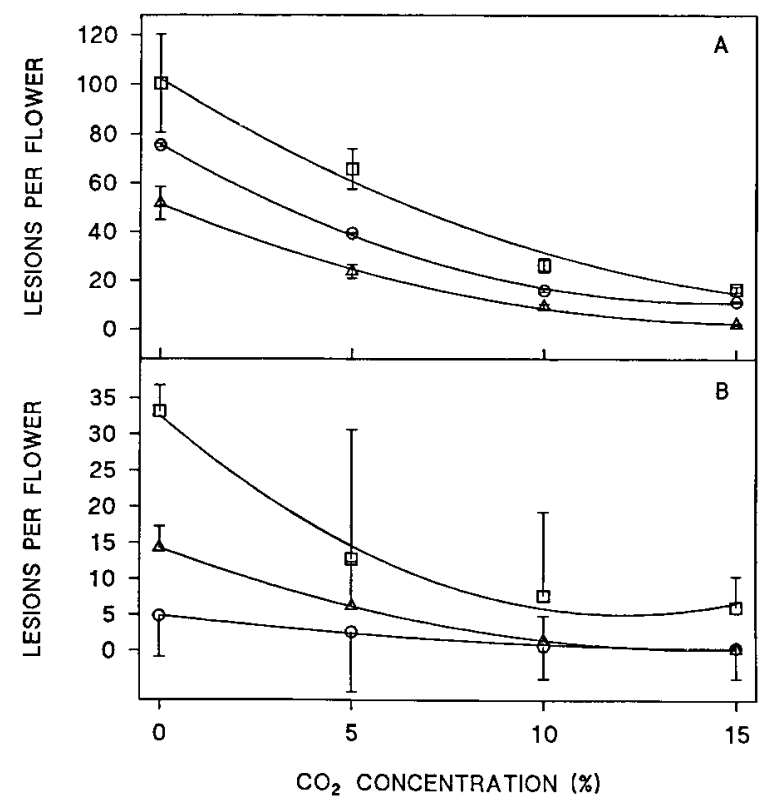

Fig. 2. Effect of $\mathrm{CO}_{2}$ concentration on development of $B$. cinerea lesions of three cultivars of cut roses during storage at $2.5 \mathrm{C}$ (Expt. II). Points are the means of four replicates \pm SD (A) Flowers inoculated with $B$. cinerea conidia before storage. Equations are: 'Royalty' (ㅁ) $\mathrm{Y}=102-9.5(\mathrm{X})+0.25\left(\mathrm{X}^{2}\right), R^{2}=0.89, P<$ 0.001; 'Sonia' (O) Y $=76-9.0(\mathrm{X})+0.32\left(\mathrm{X}^{2}\right), R^{2}=0.95, P$ $<0.001$; 'Gold Rush' $(\triangle) \mathrm{Y}=51-6.4(\mathrm{X})+0.21\left(\mathrm{X}^{2}\right) R^{2}=$ $0.96, P<0.001$. (B) Noninoculated flowers. Equations are: 'Royalty' $\mathrm{Y}=36-4.6(\mathrm{X})+0.19\left(\mathrm{X}^{2}\right), R^{2}=0.49, P=0.012$; 'Sonia' $\mathrm{Y}=4.9-0.6(\mathrm{X})+0.02\left(\mathrm{X}^{2}\right), R^{2}=0.89, P<0.001$; 'Gold Rush' Y $=14.9-2.1(\mathrm{X})+0.08\left(\mathrm{X}^{2}\right), R^{2}=0.70, P<0.003$.

Table 1. Analysis of variance for the effects of $\mathrm{CO}_{2}$ concentration and inoculation on development of $B$. cinerea lesions on three cultivars of cut roses (Expt. II).

\begin{tabular}{llrr}
\hline \hline Source & df & F & PR $>$ F \\
\hline Inoculation & 1 & 229.9 & $<0.001$ \\
Carbon dioxide & 3 & 92.1 & $<0.001$ \\
Cultivar & 2 & 38.8 & $<0.001$ \\
Carbon dioxide $\times$ inoculation & 3 & 35.8 & $<0.001$ \\
Inoculation $\times$ cultivar & 2 & 11.8 & $<0.001$ \\
Carbon dioxide $\times$ cultivar & 6 & 3.5 & 0.006 \\
\hline
\end{tabular}


Table 2. Effects of $\mathrm{CO}_{2}$ treatment during storage at $2.5 \mathrm{C}$ on vase life, leaf damage, and time to peak fresh weight of three cultivars of cut roses (Expt. II). Carbon dioxide treatments were applied for the first 5 days of a 7 -day cold-storage period. After storage, flowers were transferred to $21 \mathrm{C}$ for vase life evaluation. Leaf damage was scored 7 days later.

\begin{tabular}{|c|c|c|c|c|c|c|c|c|c|c|}
\hline \multirow{3}{*}{$\begin{array}{l}\text { Carbon dioxide } \\
\text { concn } \\
(\%)\end{array}$} & & \multicolumn{3}{|c|}{$\begin{array}{c}\text { Roses discarded } \\
\text { prematurely }(\%)^{\mathrm{z}}\end{array}$} & \multicolumn{3}{|c|}{$\begin{array}{c}\text { Leaf damage } \\
\text { (\% unacceptable roses) }\end{array}$} & \multicolumn{3}{|c|}{$\begin{array}{l}\text { Time to peak fresh weight } \\
\text { (days after storage) }^{\mathbf{x}}\end{array}$} \\
\hline & & \multicolumn{3}{|c|}{ Cultivar } & \multicolumn{3}{|c|}{ Cultivar } & \multicolumn{3}{|c|}{ Cultivar } \\
\hline & & Sonia & Gold Rush & Royalty & Sonia & Gold Rush & Royalty & Sonia & Gold Rush & Royalty \\
\hline $\begin{array}{l}0 \\
5 \\
10 \\
15\end{array}$ & & $\begin{array}{l}79 \mathrm{a} \\
63 \mathrm{a} \\
21 \mathrm{~b} \\
17 \mathrm{~b}\end{array}$ & $\begin{array}{r}58 \mathrm{a} \\
13 \mathrm{~b} \\
8 \mathrm{~b} \\
4 \mathrm{~b}\end{array}$ & $\begin{array}{l}83 \mathrm{a} \\
46 \mathrm{~b} \\
67 \mathrm{ab} \\
42 \mathrm{~b}\end{array}$ & $\begin{array}{c}0 \\
0 \\
13 \mathrm{a} \\
38 \mathrm{a}\end{array}$ & $\begin{array}{l}0 \\
0 \\
0 \\
0\end{array}$ & $\begin{array}{c}0 \\
0 \\
4 \mathrm{a} \\
50 \mathrm{~b}\end{array}$ & $\begin{array}{l}4.6 \mathrm{a} \\
4.9 \mathrm{ab} \\
5.4 \mathrm{bc} \\
5.5 \mathrm{c}\end{array}$ & $\begin{array}{l}4.0 \mathrm{a} \\
4.8 \mathrm{~b} \\
4.9 \mathrm{~b} \\
5.0 \mathrm{~b}\end{array}$ & $\begin{array}{l}3.8 \mathrm{a} \\
4.2 \mathrm{ab} \\
4.4 \mathrm{ab} \\
4.6 \mathrm{~b}\end{array}$ \\
\hline
\end{tabular}

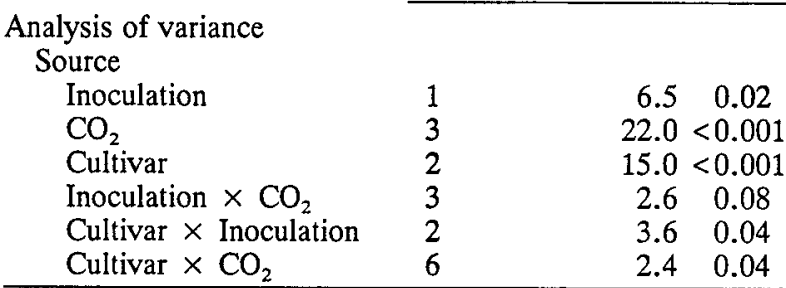

${ }^{2}$ Percentage of roses discarded before the end of vase life evaluation because of $B$. cinerea-induced petal abscission or maceration of the receptacles. Statistical analysis was performed on arcsin square root-transformed data. Nontransformed means are presented. Mean separation by Waller-Duncan $\mathrm{k}$-ratio $t$ test $(\mathrm{k}=100)$.

YStatistical analysis performed on arcsin square root-transformed data. Nontransformed means are presented. Mean separation within columns by $t$ tests $(\alpha=0.05)$.

Mean separation by Waller-Duncan k-ratio $t$ test $(\mathrm{k}=100)$.

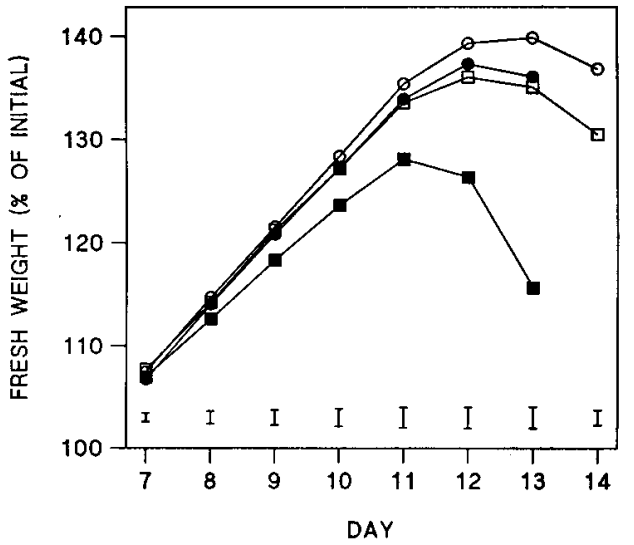

Fig. 3. Changes in fresh weight of cut 'Sonia' roses after storage at $2.5 \mathrm{C}$ in air $(\square)$ or $10 \% \mathrm{CO}_{2}(0)$ (Expt. II). $\mathrm{CO}_{2}$ treatments were applied for the first 5 days of the 7-day cold-storage period. Solid symbols represent flowers inoculated with $B$. cinerea conidia before storage. Open symbols represent noninoculated flowers. Vertical bars represent the SE of the mean for each day, $n=4$. The main effect of inoculation on peak fresh weight was highly significant $(P=$ $0.008)$. The main effect of $\mathrm{CO}_{2}$ concentration and the interaction between concentration and inoculation were not significant $(P>$ $0.28)$.

in the solutions. Sulfur dioxide-induced leaf damage was scored 7 days after removal from storage using the following hedonic scale: 0 = no visible damage $; 1=$ limited necrotic areas around wounds, $<1 \mathrm{~mm}$ diameter; $2=$ necrotic areas 1 to $5 \mathrm{~mm}$ around wounds; 3 = necrotic areas 5 to $10 \mathrm{~mm}$ around wounds and/ or at leaf margins; and $4=>30 \%$ of the leaf necrotic. The

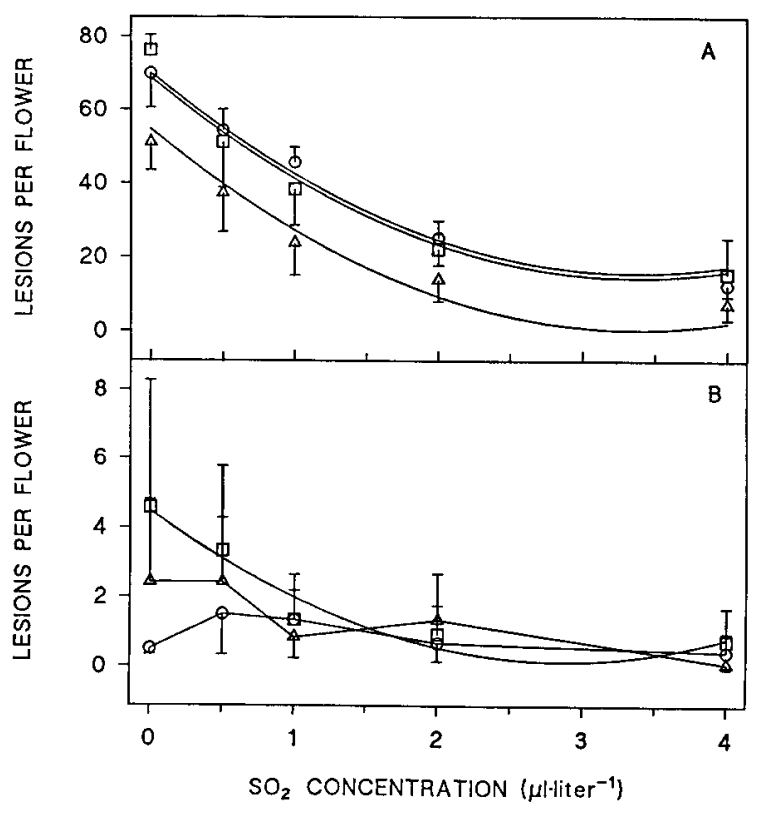

Fig. 4. Effect of $\mathrm{SO}_{2}$ concentration on the development of $B$. cinerea lesions on three cultivars of cut roses during storage at $2.5 \mathrm{C}$ (Expt. III). Points are the means of four replicates \pm SD. (A) Flowers inoculated with $B$. cinerea conidia before storage. Since the slopes for the cultivars were not different from each other $(P>0.4)$, a single model was fit $\left(R^{2}=0.86, P<0.001\right)$. Indicator variables were used to estimate the different intercepts. Equations are: 'Royalty' ( $\square$ ) $\mathrm{Y}=69-32.3(\mathrm{X})+4.8\left(\mathrm{X}^{2}\right)$; 'Sonia' (O) $\mathrm{Y}=70-$ $32.3(\mathrm{X})+4.8\left(\mathrm{X}^{2}\right)$; 'Gold Rush' $(\triangle) \mathrm{Y}=55-32.3(\mathrm{X})+4.8\left(\mathrm{X}^{2}\right)$. (B) Noninoculated flowers. For 'Royalty', $Y=4.5-3.04(X)+$ $0.53\left(\mathrm{X}^{2}\right), R^{2}=0.32, P=0.045$. The effect of $\mathrm{SO}_{2}$ concentration was not significant for 'Sonia' or 'Gold Rush'.

J. Amer. Soc. Hort. Sci. 115(1):102-107. 1990.

$\begin{array}{llll}0.0 & 0.99 & 8.2 & 0.009 \\ 9.1 & <0.001 & 14.5 & <0.001 \\ 6.1 & 0.004 & 18.7 & <0.001 \\ 0.02 & 0.99 & 0.5 & 0.71 \\ 1.5 & 0.23 & 5.4 & 0.008 \\ 4.1 & 0.002 & 1.0 & 0.43\end{array}$


Table 3. Analysis of variance for the effects of $\mathrm{SO}_{2}$ concentration and inoculation on development of $B$. cinerea lesions on three cultivars of cut roses (Expt. III).

\begin{tabular}{lcrc}
\hline \hline Source & df & F & PR $>F$ \\
\hline Inoculation & 1 & 648.2 & $<0.001$ \\
Sulfur dioxide & 4 & 56.5 & $<0.001$ \\
Cultivar & 2 & 29.4 & $<0.001$ \\
Sulfur dioxide $\times$ inoculation & 4 & 48.1 & $<0.001$ \\
Inoculation $\times$ cultivar & 2 & 29.2 & $<0.001$ \\
Sulfur dioxide $\times$ cultivar & 8 & 2.0 & 0.05 \\
\hline
\end{tabular}

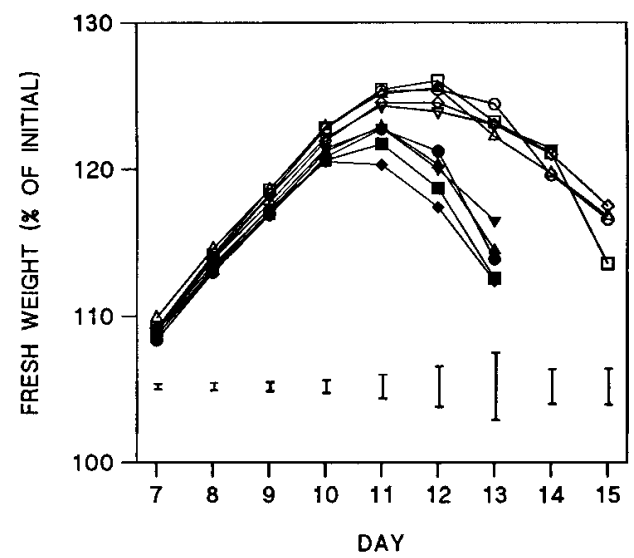

Fig. 5. Changes in fresh weight of cut roses after storage for 7 days at $2.5 \mathrm{C}$ in air mixed with $0(\square), 0.5(0), 1.0(\triangle), 2.0(\nabla)$, or 4.0 $(\diamond) \mu \mathrm{l} \cdot \mathrm{liter}^{-2} \mathrm{SO}_{2}$ (Expt. III). Solid symbols represent flowers inoculated with $B$. cinerea conidia before storage. Open symbols represent noninoculated flowers. Vertical bars represent the SE of the mean for each day, $n=12$ (the cultivars were pooled). The effects of inoculation on peak fresh weight and time to peak fresh weight were highly significant $(P<0.001)$. The main effects of $\mathrm{SO}_{2}$ concentration and the interactions between concentration and inoculation were not. significant $(P>0.56)$.

rating for each rose was based on the most severely damaged leaf. A rating of 3 or greater was considered commercially unacceptable.

This experiment was a complete factorial with five $\mathrm{SO}_{2}$ concentrations, two inoculation levels, and three cultivars in a splitplot design. Sulfur dioxide concentration and inoculation were the main plot factors and cultivar was the subplot factor. The main plots, subplots, number of replications, and statistical treatment were the same as those described for Expt. II. The experiment was repeated and the data were pooled for analysis.

\section{Results}

Experiment I. Disease severity decreased with increasing $\mathrm{CO}_{2}$ concentration. There were no significant differences between the slopes or intercepts of the transformed regression lines for 5- and 7-day $\mathrm{CO}_{2}$ treatments $(P>0.27$, Fig. 1). Leaf discoloration increased with both $\mathrm{CO}_{2}$ concentration and treatment duration. The leaves of roses treated with $20 \% \mathrm{CO}_{2}$ for 5 or 7 days were severely discolored and were judged commercially unacceptable, as were those treated with $10 \% \mathrm{CO}_{2}$ for 7 days. The leaves of roses treated with $10 \% \mathrm{CO}_{2}$ for 5 days or $5 \%$ $\mathrm{CO}_{2}$ for 7 days had very little discoloration and were judged acceptable. No leaf discoloration was visible on roses treated with $5 \% \mathrm{CO}_{2}$ for 5 days or on roses treated for 3 days with any $\mathrm{CO}_{2}$ concentration.

Some noninoculated roses stored in $0 \%$ to $20 \% \mathrm{CO}_{2}$ for 7 days were held in air at $2.5 \mathrm{C}$ for 1 additional day before transfer to $21 \mathrm{C}$. For each $\mathrm{CO}_{2}$ concentration, this caused less leaf discoloration than transfer to air at room temperature immediately after 7 days of high- $\mathrm{CO}_{2}$ storage.

Experiment II. Carbon dioxide treatment reduced disease development on inoculated and noninoculated flowers of all the cultivars tested, and there was a significant interaction between $\mathrm{CO}_{2}$ concentration and inoculation (Fig. 2, Table 1). Carbon dioxide treatment also reduced the percentage of roses that were discarded prematurely (before the end of the vase life evaluation period) because of maceration of the receptacles or $B$. cinereainduced petal abscission (Table 2).

No abnormal opening or petal phytotoxicity (e.g., bluing) was observed at any $\mathrm{CO}_{2}$ concentration. Carbon dioxide-induced leaf damage was not observed upon removal from storage, but became visible after 2 to 3 days at room temperature as areas of brownish-bronze discoloration. The severity of leaf damage was highly cultivar-dependent and increased with $\mathrm{CO}_{2}$ concentration (Table 2).

Noninoculated roses gained more fresh weight and reached peak fresh weight later than inoculated roses, but these effects were significant only for 'Sonia' (Fig. 3). Roses stored in $\mathrm{CO}_{2}$ enriched atmospheres gained more fresh weight and reached peak fresh weight later than those stored in air (Table 2, Fig. 3 ). The effects of $\mathrm{CO}_{2}$ treatment on peak fresh weight and time to peak fresh weight were uniform across the cultivars and inoculum levels (Table 2).

Experiment III. Sulfur dioxide treatment during storage also reduced disease development (Fig. 4, Table 3). On inoculated roses of each cultivar, disease control increased with increasing $\mathrm{SO}_{2}$ concentration. Regression analysis using indicator variables and partial $\mathrm{F}$ tests for the cultivars showed that the intercepts of the $\mathrm{SO}_{2}$ concentration-disease severity regression lines were different for each cultivar $(P<0.001)$, but the slopes were not different $(P>0.4)$. The effect of $\mathrm{SO}_{2}$ concentration on disease severity on noninoculated flowers was significant only for 'Royalty' (Fig. 4). Sulfur dioxide treatment had no significant effect on the percentage of roses that were discarded prematurely because of maceration of the receptacles or $B$. cinerea -induced petal abscission (Table 4).

Storage in $4 \mu \mathrm{SO}_{2} /$ liter bleached the marginal 2 to $3 \mathrm{~mm}$ of 'Sonia' and 'Royalty' flower petals. The bleached areas became necrotic after 1 to 2 days at 21C. Bleaching and necrosis of leaves caused by $\mathrm{SO}_{2}$ treatment was visible immediately after cold storage. The severity of the damage increased with $\mathrm{SO}_{2}$ concentration and was similar for all the cultivars (Table 4).

Noninoculated roses gained more fresh weight and reached peak fresh weight later than inoculated roses (Fig. 5). Sulfur dioxide concentration had no significant effect on the pattern of fresh weight gain $\left(P=0.69\right.$ and 0.96 for effects of $\mathrm{SO}_{2}$ concentration on peak fresh weight and time to peak fresh weight, respectively).

\section{Discussion}

Carbon dioxide- and $\mathrm{SO}_{2}$-enriched atmospheres reduced the severity of $B$. cinerea infections of cut roses during storage, but foliar damage limited the useful concentration ranges. In Expt. I, discontinuing $\mathrm{CO}_{2}$ treatment for the last 2 days of cold storage reduced leaf damage without loss of disease control. Treatment with $10 \% \mathrm{CO}_{2}$ for the first 5 days of the 7-day cold storage 
Table 4. Effects of $\mathrm{SO}_{2}$ treatment during storage for 7 days at $2.5 \mathrm{C}$ on vase life and leaf damage of three cultivars of cut roses (Expt. III). After storage, flowers were transferred to $21 \mathrm{C}$ for vase life evaluation. Leaf damage was scored 7 days later.

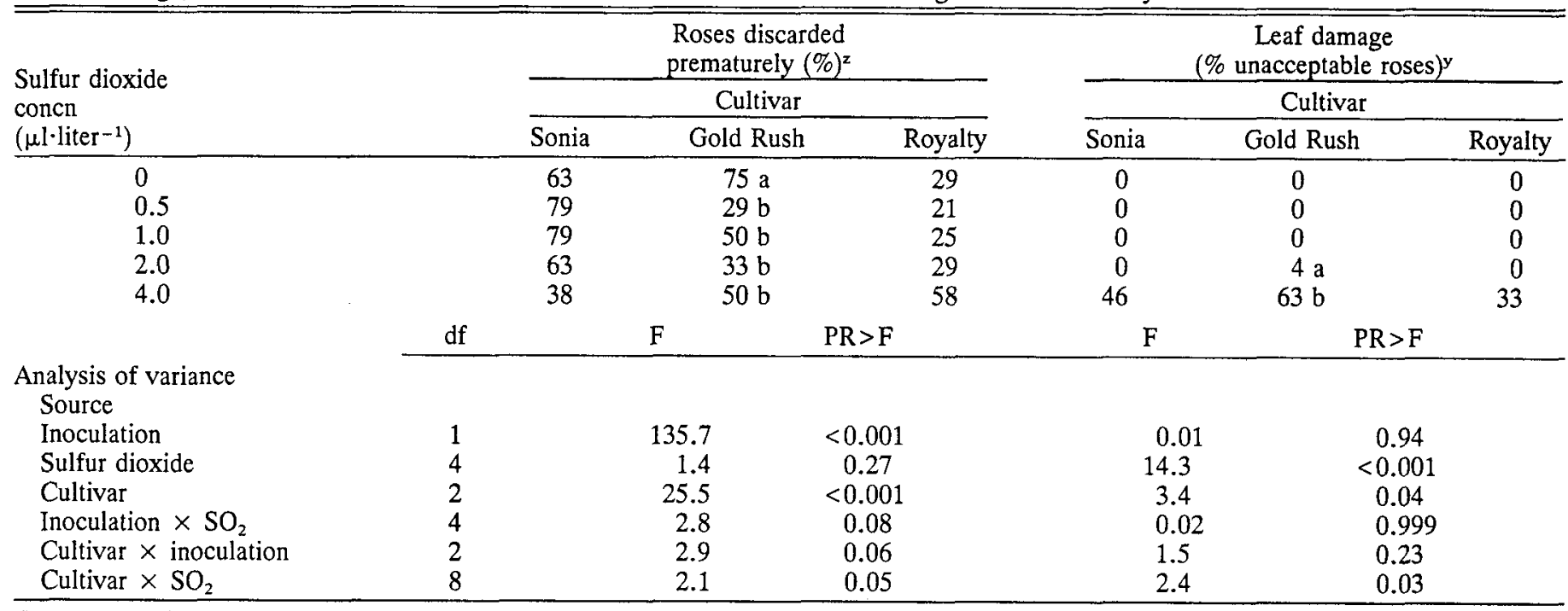

zPercentage of roses discarded before the end of vase life evaluation because of $B$. cinerea-induced petal abscission or maceration of the receptacles. Statistical analysis was performed on arcsin square root-transformed data. Nontransformed means are presented. Mean separation by Waller-Duncan $\mathrm{k}$-ratio $t$ test $(\mathrm{k}=100)$.

y Mean separation within column by $t$ test $(\alpha=0.05)$.

period yielded the greatest disease reduction without unacceptable leaf damage. This $\mathrm{CO}_{2}$ treatment was selected as the center point for further study.

In Expt. II the average disease reduction in $10 \% \mathrm{CO}_{2}$ (compared to air controls) was $77 \%$ for experimentally inoculated flowers and $82 \%$ for noninoculated flowers. This result is comparable to the degree of disease control achieved with postharvest treatments of the fungicides vinclozolin or iprodione under similar laboratory conditions (Hammer and Marois, 1988; Redmond et al., 1987).

Background disease levels for the $\mathrm{SO}_{2}$ experiment (Expt. III) were low compared to those for the $\mathrm{CO}_{2}$ experiments. While $\mathrm{SO}_{2}$ treatment did not significantly reduce these naturally occurring infections on 'Sonia' and 'Gold Rush', the significant disease reduction on noninoculated 'Royalty' flowers indicates that $\mathrm{SO}_{2}$ will control the resident infections encountered commercially. At nonphytotoxic $\mathrm{SO}_{2}$ concentrations $\left(<2 \mu \mathrm{l} \cdot\right.$ liter $\left.^{-1}\right)$, however, the degree of disease control was lower than that achieved with $\mathrm{CO}_{2}$.

Greater fresh weight gain and longer time to peak fresh weight are correlated with delayed senescence and other, more subjective, measures of cut flower quality (Brantley, 1975; Marousky, 1971; Sacalis, 1974). In the present experiments, as in previous studies (Hammer and Marois, 1988, 1989), disease reduced flower quality and vase life. This effect is shown in the lower peak fresh weights and shorter times to peak fresh weight caused by laboratory inoculation when the background infection levels were low (Figs. 3 and 5). The fungistatic storage atmospheres mitigated these effects of $B$. cinerea on the quality of inoculated flowers, but not as well as fungicidal dips or other control measures under similar experimental conditions (Hammer and Marois, 1988, 1989). We attribute this difference to greater disease control and residual activity of the fungicides, which, unlike fungistatic atmospheres, persist after storage.

Carbon dioxide treatment during storage increased poststorage weight gain and slowed bud opening, as reflected in the longer time to reach peak fresh weight. These beneficial effects of $\mathrm{CO}_{2}$ treatment (i.e., controlled-atmosphere storage) have been documented previously (Joyce and Reid, 1986; Rogers, 1973; Staby et al., 1982). Sulfur dioxide treatment had no such effects on opening or vase life.

Few 'Royalty' and no 'Gold Rush' roses sustained severe leaf damage from storage in $10 \% \mathrm{CO}_{2}$, but $13 \%$ of the 'Sonia' were unacceptable because of leaf damage. Visible foliar discoloration developed only after transfer to $21 \mathrm{C}$; no necrosis was observed at $5 \%$ to $20 \% \mathrm{CO}_{2}$ in any cultivar. Also, the results of Expt. I suggest that the shortened duration of $\mathrm{CO}_{2}$ treatment may not be as important in mitigating leaf damage as a recovery period in air at $2.5 \mathrm{C}$ before transfer to room temperature. These observations and the significant differences in susceptibility to leaf damage among cultivars suggest that the leaf discoloration is a physiological disorder, perhaps similar to the brown stain of stored lettuce described by Brecht et al. (1973a, 1973 b). In contrast, the foliar and petal damage caused by $\mathrm{SO}_{2}$ was chemical bleaching and was not highly cultivar-dependent. Shortening the exposure time probably would not mitigate such chemical damage to the same extent as it did $\mathrm{CO}_{2}$-induced discoloration.

While the use of fungistatic atmospheres obviates the residue and fungicide tolerance problems associated with postharvest dip treatments, the degree of disease control achieved with $\mathrm{SO}_{2}$ or $\mathrm{CO}_{2}$ treatment at nonphytotoxic concentrations was lower than that attainable with conventional fungicides (Hammer and Marois, 1988; McCain and Welch, 1982; Redmond et al., 1987) or nonchemical methods (Hammer and Marois, 1989) and may not be useful commercially. Carbon dioxide treatment offers greater potential than $\mathrm{SO}_{2}$ treatment, since greater disease control was achieved at nonphytotoxic levels.

\section{Literature Cited}

Brantley, R.K. 1975. A new postharvest chemical treatment for roses. HortScience 10:178-179.

Brecht, P,E., A.A. Kader, and L.L. Morris. 1973a. Influence of post- 
harvest temperature on brown stain of lettuce. J. Amer. Soc. Hort. Sci. 98:399-402.

Brecht, P.E., A.A. Kader, and L.L. Morris. 1973b. The effect of composition of the atmosphere and duration of exposure on brown stain of lettuce. J. Amer. Soc. Hort. Sci. 98:536-538.

Carre, D.D. 1984. The influence of atmospheric humidity and free water on germination and germ tube growth of Botrytis cinerea Pers. MS Thesis, Oregon State Univ., Corvallis.

Cline, M.N. and C.E. Bardsley. 1984. Post-harvest treatment of cut flowers for Botrytis blight. Proc. Brit. Crop Protect. Conf. 3:11691173.

Dahlenburg, A.P., K.J. Gillespie, and L.D. Jarret. 1979. Postharvest handling of table grapes. Dept. of Agr., South Australia. Hort. Notes 4.

Hammer, P.E. and J.J. Marois. 1988. Postharvest control of Botrytis cinerea on cut roses with picro-cupric-ammonium formate. Plant Dis. 72:347-350.

Hammer, P.E. and J.J. Marois. 1989. Nonchemical methods for postharvest control of Botrytis cinerea on cut roses. J. Amer. Soc. Hort. Sci. 114:100-106.

Harvey, J.M. 1982. $\mathrm{CO}_{2}$ atmospheres for truck shipments of strawberries, p. 359-365. In: D.G. Richardson and M. Meheriuk (eds.). Controlled atmospheres for storage and transport of perishable agricultural commodities. Timber Press, Beaverton, Ore.

Joyce, D.C. and M.S. Reid. 1986. Effects of pathogen-suppressing modified atmospheres on stored cut flowers, p. 185-198. In: S.M. Blankenship (ed.). Controlled atmospheres for storage and transport of perishable agricultural commodities. Dpt. Hort. Sci., North Carolina State Univ., Raleigh. Hort. Rpt. 126.
Longley, L.E. 1933. Some effects of storage of flowers in various gases at low temperatures on their keeping qualities. Proc. Amer. Soc. Hort. Sci. 30:607-609.

Marousky, F.J. 1971. Inhibition of vascular blockage and increased moisture retention in cut roses induced by $\mathrm{pH}, 8$-hydroxyquinoline citrate, and sucrose. J. Amer. Soc. Hort. Sci. 96:38-41.

Maude, R.B. 1980. Disease control, p.275-308. In: J.R. Coley-Smith, K. Verhoeff, and W.R. Jarvis(eds.). The biology Botrytis. Academic, London.

McCain, A. and K.E. Welch. 1982. Controlling gray mold of rose flowers. Univ. of California Coop. Ext. Serv. Flower and Nursery Rpt. Spring 1982. p. 6.

Nelson, K.E. 1985. Harvesting and handling California table grapes for market. Univ of California Agr. Expt. Sta. Bul. 1913.

Phillips, D.J., D.A. Margosan, and D.C. Fouse. 1985. Postharvest control of Botrytis rot of roses with carbon dioxide. Plant Dis. 69:789790.

Redmond, J.C., J.J. Marois, and J.D. MacDonald. 1987. Biological control of Botrytis cinerea on roses with epiphytic microorganisms. Plant Dis. 71:799-802.

Rogers, M.N. 1973. An historical and critical review of postharvest physiology research on cut flowers. HortScience 8:189-194.

Sacalis, J.N. 1974. Inhibition of vascular blockage and extension of vase life in cut roses with an ion exchange column. HortScience 9:149-151.

Staby, G.L., J.W. Kelley, and M.S. Cunningham. 1982. Floral crop storage. p. 239-266. In: D.G. Richardson and M. Meheriuk (eds.). Controlled atmospheres for storage and transport of perishable agricultural commodities. Timber Press, Beaverton, Ore. 